\title{
Empowerment of family caregiver in front of stroke in hospital environment
}

\author{
Empowerment do familiar cuidador frente ao acidente vascular cerebral no ambiente hospitalar
}

Empowerment del cuidador de familiar delante de accidente vascular cerebral em entorno hospitalario

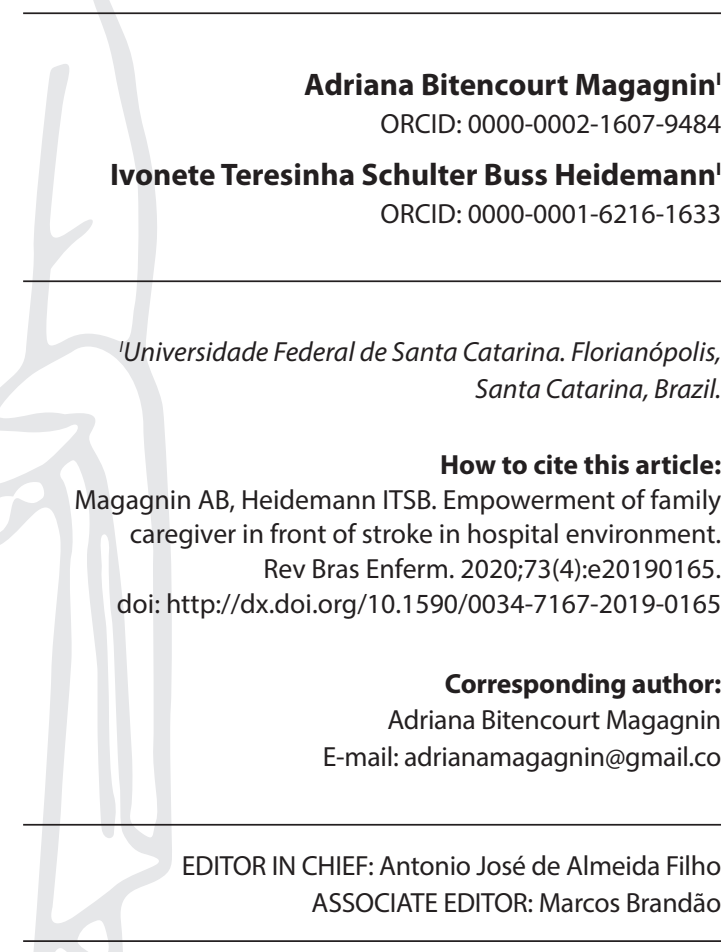

Submission: 03-06-2019 Approval: 10-10-2019

\begin{abstract}
Objectives: to understand how the empowerment of family caregivers of people with stroke occurs in the hospital environment. Methods: a qualitative research, participatory action research, articulated with Paulo Freire's Research Itinerary, developed in April 2018 with family caregivers, in a Stroke Unit. Results: three predominant codes were coded: the need for empowerment and autonomy to experience the care situation; the challenges experienced in becoming a caregiver; and family support. Participants presented a lack of information inherent to the care process, with distancing from empowerment to perform the function in dehospitalization. Dialogue revealed empowerment as a possibility for critical awareness and skill development. Conclusions: it highlights the importance of directing health promotion for caregivers, inserting them in the care process, recognizing their needs and intensifying practices that promote empowerment for care, bypassing curative actions. Descriptors: Family Caregiver; Stroke; Power; Health Promotion; Hospital.
\end{abstract}

\section{RESUMO}

Objetivos: compreender como o empowerment dos familiares cuidadores de pessoas acometidas por acidente vascular cerebral ocorre no ambiente hospitalar. Métodos: pesquisa qualitativa, do tipo pesquisa ação participante, articulada com o Itinerário de Pesquisa de Paulo Freire, desenvolvida em abril de 2018 com familiares cuidadores, em uma Unidade de Acidente Vascular Cerebral. Resultados: foram codificados três predominantes: a necessidade de empowerment e autonomia para vivenciarem a situação de cuidado; os desafios vivenciados ao tornar-se cuidador; e o apoio familiar. As participantes apresentaram carência de informações inerentes ao processo de cuidar, com distanciamento do empowermentpara exercer a função na desospitalização. O diálogo revelou o empowermentcomo possibilidade para a consciência crítica e o desenvolvimento de habilidades. Conclusões: destaca-se a importância de direcionar a promoção da saúde para cuidadores, inserindo-os no processo de cuidado, reconhecendo suas necessidades e intensificando as práticas que promovam o empowerment para o cuidado, perpassando as ações curativistas. Descritores: Familiar Cuidador; Acidente Vascular Cerebral; Poder; Promoção da Saúde; Hospital.

\section{RESUMEN}

Objetivos: comprender cómo se produce el empowerment de los cuidadores familiares de personas conaccidente cerebrovascular em el entorno hospitalario. Métodos:investigación cualitativa, investigación de acción participativa, articulada conelltinerario de Investigación de Paulo Freire, desarrolladoen abril de 2018 con cuidadores familiares, en una Unidad de Accidentes Cerebrovasculares. Resultados: se codificaron tres códigos predominantes: la necesidad de empowerment y autonomía para experimentar lasituaciónasistencial; Los desafíos experimentados para convertirse em un cuidador; y apoyo familiar. Los participantes carecían de informacióninherente al proceso de atención, con distanciamiento del empowerment para realizar la función de deshospitalización. El diálogo revelo el empowerment como una posibilidad para laconciencia crítica y eldesarrollo de habilidades. Conclusiones: destacamos laimportancia de dirigir lapromoción de lasalud para los cuidadores, incluyéndolos em elproceso de atención, reconociendo sus necesidades e intensificando lasprácticas que promuevenelempoderamiento para laatención, evitando lasacciones curativas.

Descriptores: Familiar Cuidador; AccidenteCerebrovascular; Poder; Promoción de laSalud; Hospital. 


\section{INTRODUCTION}

Health Promotion emerges strongly in the late 70's as a new thinking about health, considering a positive concept and aiming to move away from the only biologicist and curative approach to health practices ${ }^{(1)}$. The first international conference on the topic was held in Ottawa, Canada, in 1986. This meeting originated the Ottawa Charter, a key document used today as a basis for thinking about Health Promotion. It establishes five strategic axes for the realization of the ideals explained, including the creation of healthy public policies, health-friendly environments, development of personal skills, reorientation of health services and reinforcement of community action (social empowerment) ${ }^{(2-3)}$.

Moreover, it is emphasized that Health Promotion cannot be limited to Primary Health Care services, despite the strong relationship existing and understood by the greater contact with people and the community. Health services reorientation promotes that there should be a transversal action, covering all points of the Care Network, including highly complex services. Although curative actions are essential, practices guided by physical aspects make Health Promotion a secondary objective in these environments ${ }^{(4)}$.

The Health Promoting Hospital (HPH) movement, linked to the World Health Organization, emerged in the late 1980s, advocating health-promoting actions that involve the environment, communities, the organization of the institution, health professionals, people and their families. In 2004 the organization created the "Standards for Health Promotion in Hospitals" (5), a document that includes five main axes, focusing on patients, staff and management: a) an institutional policy that involves health promotion; b) the importance of recognizing patients' needs for health promotion, prevention and rehabilitation; c) make available to the patient information related to their health situation and implementation of health promoting practices; d) the institution's responsibility to provide a healthy work environment and; e) intersectoriality and cooperation among other health services.

The current health model challenges managers to new alternatives that can meet the demands of the demographic transition, configuring a population with increasingly older people due to increased life expectancy. Thus, it culminated in the increase of Chronic Noncommunicable Diseases. Among these conditions, cerebrovascular diseases, such as stroke, occupy the first place in situations that lead to physical and/or cognitive disabilities and, naturally, dependence ${ }^{(6-7)}$.

In this scenario, the family caregiver appears as the main figure to meet the needs of people with stroke, starting this role even in the hospital context. From the perspective of Health Promotion, the inclusion of caregivers in care planning and health team work routines can assist in empowering these individuals, corroborating the Ottawa Charter, which focuses on the need to strengthen community action. and in the development of personal skills. The English term expresses the ability of people and communities to pursue quality of life, including active participation in this movement ${ }^{(3,8)}$.

In the light of the critical-social perspective, this empowerment process aims at individual and/or social awareness from a critical reflection of the lived reality, believing in the potential of people and communities for transformation. The thinker Paulo Freire contributed with his writings in this aspect, when explaining about the existing relations of domination and the necessity of liberation and empowerment for the achievement of autonomy. For Freire, the English term seeks to overcome models of domination, characterizing power relations with the other, necessary for awareness and social transformation. In the concept of autonomy, it relates to the ability to act for oneself and responsibly ${ }^{(9-10)}$.

In a hospital setting, stroke disability requires that a family member or network of friends provide care that allows the survivor to return home. In the perception of these informal caregivers, there is little understanding by hospital professionals about the needs that arise after discharge, such as the daily issues of a person with stroke ${ }^{(11)}$.

\section{OBJECTIVES}

To understand how the empowerment of family caregivers of people with stroke occurs in the hospital environment.

\section{METHODS}

\section{Ethical aspects}

The research began after the project was approved by the Research Ethics Committee of the Universidade Federal de Santa Catarina (UFSC) and authorized by the hospital institution. The ethical and legal components are present at all stages of the research, in accordance with Resolution 466/12 of the Brazilian National Health Board (Conselho Nacional de Saúde). The Informed Consent Form (ICF) was signed by the research participants, and to ensure anonymity they were identified as FC1, FC2 and so on.

\section{Type of study andTheoretical-methodological framework}

This is a qualitative study described as a participant action, based on the methodological framework of Paulo Freire's Research Itinerary, involving three interdependent moments: Thematic Investigation, Coding and Decoding and Critical Unveiling. The research was operationalized through four Culture Circles that took place in April 2018. These meetings represent a space where people who experience similar boundary situations, exchange experiences and collectively seek themes of interest to reflect and unveil ${ }^{(9)}$. For theoretical guidance, the concepts of Health Promotion were used, focusing on the concept of empowerment, understood by the critical-social perspective ${ }^{(10)}$.

\section{Study setting}

The study was conducted in the city of Joinville, located in the north of the state of Santa Catarina, which has a municipal public hospital that offers specialized care to people with stroke, having a stroke unit to assist in the rehabilitation phase of the a 21-bed Full Stroke Unit disease. Historically, the unit seeks the insertion of caregivers in team actions.

\section{Data source}

For participation, the inclusion criteria of this study were: being a family caregiver of individuals admitted to the Stroke Unit; be 
present for at least 48 hours in the unit, and participate in Circle discussions. For the exclusion criteria, we adopted: being a formal caregiver; be caregiver of a person who is not hospitalized due to stroke in the referred unit, considering here possible situations that beds could be available for other specialties. Participation occurred irregularly, due to the turnover of people who were discharged. Paulo Freire's Research Itinerary allows the Circles to be made with a small and heterogeneous number of participants, since it is a dynamic method and allows a horizontal dialogic relationship between the research participants, and in each meeting the themes are resumed and contextualized ${ }^{(9)}$. This investigation was conducted with 16 family caregivers of the referred unit. Data collectionwasperformedbythemainresearcher.

\section{Collection and organization of data, and data analysis}

Prior to the study, the researcher inserted herself in the Stroke Unit, in order to know the team's routines, to introduce herself to the caregivers, stating her goal with the research, in order to sensitize their participation in the meetings. for participation). Some caregivers could not participate, justified by the change of companions at the time of the meeting or waiting for the medical report.

Throughout the four Culture Circles, all the stages were developed and the meetings were previously scheduled, with an average duration of 90 minutes, developed in a classroom located in the hospital institution. The socioeconomic data of all participants at the beginning of the research were investigated.

To boost discussions, the mediator used dynamics and activities that stimulated the participation of caregivers. After the presentation and approach, to initiate the Thematic Investigation was launched to the group triggering questions: I) How do you feel as a caregiver? II) What are the biggest challenges for empowering yourself as a caregiver? III) What are the greatest facilities/potentialities for empowering and promoting stroke health? The participants reflected in pairs and with the help of magazines and tags expressed their perceptions for the large group. The term "empowerment" was initially inserted along with the triggering issues in order to boost debate with participants in the Culture Circles. The meaning that participants expressed about empowerment was the main focus of reflection and action in the meetings. From these questions, 40 themes emerged, related to the realities experienced and understood by family caregivers as important to raise. In the second Culture Circle, the researcher took tags with the themes raised and encouraged the group to revisit, read, reflect and start the stages of Coding and Decoding and Critical Unveiling. It was discussed about the predominant themes in the discussions, and the organization of the next meetings was agreed, as well as the order of priority of the 40 themes for reflection, which were codified into three main themes, including a) the need for family support, b) to be caregiver, and c) empowerment and autonomy.

In the third Culture Circle, dynamics were used to encourage debate such as watching videos that portrayed situations similar to the experiences of the participants.

In the last Culture Circle, the dialogue included Decoding and Unveiling the Empowerment/Autonomy theme. To boost the unveiling of this theme, the researcher made a dynamic with a small wooden box that contained a mirror inside. They were asked to visualize the inside of the box and tell the group what they perceived in that image. The discussions made it possible to unveil about the reality experienced as caring families, as well as a rescue of empowerment, encouraging an action-reflectionaction process.

In Paulo Freire's Research Itinerary, data analysis takes place at the Critical Unveiling stage, involving all research participants. To record the themes, we used a field notebook, an audio recorder, and photographic records of the activities built by the caregivers to subsequently facilitate the organization of the themes.

\section{RESULTS}

The investigation of socioeconomic data enabled the gathering of important information from the participants, described below. There were a total of 16 family caregivers throughout the Circles, all of whom were women and most were married. Among the participants, eight declared themselves housewives, five were unemployed and the others were employed. As for the length of stay in the U-stroke, there was a variation of 2 to 15 days. Data are described in Table 1.

Table 1 - Sociodemographic characteristics of respondents, Stroke Unit, Joinville, Santa Catarina, Brazil, 2018

\begin{tabular}{llc}
\hline Characteristics & Category & N \\
\hline Sex & Female & 16 \\
& Male & 0 \\
Age & 20 to 30 years old & 3 \\
& 31 to 40 yearsold & 6 \\
& 41 to 50 years old & 1 \\
& 51 to 60 yearsold & 2 \\
Over 60 years old & 4 \\
Schooling & IncompleteElementary & 6 \\
& Complete Elementary & 2 \\
Kinship & Complete high school & 5 \\
& Graduated & 3 \\
& Daughter & 9 \\
CareLoad & Wife & 5 \\
& Cousin/Granddaughter & 2 \\
Unit hospitalization time & Full & 5 \\
& Notfull & 11 \\
& 2 to 6 days & 11 \\
& 7 to 13 days & 4 \\
& Greaterthan 13 days & 1 \\
\hline
\end{tabular}

The reflection that occurred in the Thematic Investigation phase culminated in the identification of 40 generating themes, referred to the Coding and Decoding stage. They reflect the life reality of the participants through their speech and expressed emotions. The insertion of the research question was happening naturally, permeating the desires and the need to express the daily feelings that interfered in the environment experienced by the participants. 
In the Coding and Decoding stage, the dialogue developed in the Circles allowed the manifestation of conflicting situations that interfered with women's daily lives. Among the 40 themes that emerged in the Thematic Research Culture Circles, three predominant themes were coded and decoded: 1) Being a caregiver; 2) Family Relations and 3) Empowerment and Autonomy.

This article focuses on the last theme mentioned, which emerged from 9 generating themes during the Thematic Research, as shown in Table 2.

Table 2 - Description of thematic research by family caregivers, which corresponds to the theme Empowerment and Autonomy. FullStroke Unit, Joinville, Santa Catarina, Brazil,04/2018

\section{Empowerment/Autonomy (coded, decoded and unveiled theme)}

1. The person with stroke also needs to take care

2. Need to acquire knowledge to make decisions

3. Avoid dependence on nursing for all care

4. Moments of family relief favor care

5. Friendship bonds with other caregivers

6. Caring for other unaccompanied people

7. Caregivers can assist multidisciplinary staff

8. Learnfromthisexperience

9. Support from medical and nursing staff favors care

The need to recognize themselves as people who cannot take care of the person with stroke alone was emphasized, as well as the need to be cared for as well. The opening lines portrayed fear related to insecurity, unpreparedness, and physical limitations:

I confess I'm very scared, just thinking about taking him home, serious so. I don't know what to do [...] the difficulty, for example, of getting your wheelchair in the car and getting out, taking you to a hospital, going to a clinic. For me, this is the difficulty. I won't even think too much [pause, thrilled]. I don't know what we're going to do right away. I do not know! (FC1)

This debate was motivated through dialogue in the Culture Circle, in which the family caregivers saw themselves in the mirror and told the group what they were visualizing. This made it possible for the participants to get closer, raise awareness and support each other. The dialogue on the theme of empowerment and autonomy reinforced the sensitivity so that they could criticize their living conditions, allowing possibilities for changes in their contexts, especially those related to the family and the difficulty in becoming responsible for the care after stroke, according to some statements:

Here we are used to. They [family members with stroke] are there in bed, we sit next to them [...] but they [nursing] come to take the pressure off, give the medicine. And we there. Only at home you will not be 24, 48 hours like this.You have things to do. You'll have to leave, even if it's outside to stretch and do laundry. You will not stay that time. And? I started thinking, I said to the girls .... I said "we had not stopped to think about it". (FC2)

During the Circles, there were predominant speeches that strongly referred to the need for family support for the care of the person with stroke during hospitalization. The burden of care was referred to as a reflection of the low participation of all family members during hospitalization. The caregivers expressed their needs in support of family members and reported that they were the only people responsible, especially because they are women or unemployed. Initially, the participants did not recognize themselves as autonomous in their lives, as their statements made it clear that care was a natural obligation for them. Throughout the discussions, they demonstrated reflection of the situation lived with questions about the care provided as something not valued by the family:

Why are you stressed? You don't work, you just stay with him all day [in the hospital] - They already told me. Who has never gone through this, does not know what it is. It's not sitting around all day. My mom is fine, but it's complicated. When I took care of my uncle, he was bad. Wear it! I was almost "out of the house", I had to have a treatment.(FC3)

Regarding the lack of support from the family network for care, the statements expressed insecurity, uncertainty and concerns. During the course of the discussions, some reflective thoughts were divided among the family caregivers looking for alternatives that could be found in this context. Among them, there was the possibility of support outside the family environment, as the following statement:

In my case, I'm thinking, because we are alone here [city]. I will be counting more on his friends, my neighbor, who is very friendly with him. A young boy who lives in the back of my house, who helped call the fireman, helped me [at the time of the stroke]. I'm just counting on this person there to help me. So, we rely more on the help of strangers. My children won't be able to come. (FC4)

The importance of the caregiver at this moment of hospitalization was also debated, recognizing themselves as essential actors in this context. Some statements made it clear that caregivers feel important in the hospitalization scenario, especially with regard to direct assistance with hygiene and food care that sometimes goes beyond attention to your family member and participates in the needs of others who do not have companions.

We are very participative. We help as we can. We feed other unaccompanied patients and bathe those we are taking care of. I like to know, to be able to help. I avoid calling the nurse, I do the things I can.(FC5)

Through these dialogues, they expressed the limit situations experienced, highlighting the theme empowerment and autonomy. The family caregivers acknowledged their stories and limits, but demonstrated difficulty in freeing themselves from the conflicting situations that involved care.

Changes in family routines, which focus on the care and needs of people with stroke, culminate in the insecurity of the hospital-home transition. In this scenario, some precursor factors of overload were identified, such as stress and individual limits of the family caregiver for this function, fragility in the support and social network. This includes family conflicts that directly interfere with the division of this attribution, the initial shock with the transformation of family life after illness added to the new routines and the lack of information and skills for care. 
The multidisciplinary team was not mentioned when the dialogue involved the development of personal skills in the hospital environment to perform the tasks of care. However, the participants reported confidence in the performance of health professionals regarding direct care for people with stroke, focusing on curative aspects.

In the Critical Unveiling stage, the Culture Circles were motivated by the reports of the caregivers that demonstrated challenges for care and the consequent need for empowerment in this context. These moments provided a reflection on knowledge, actions and awakenings for awareness.

Given the limits and facilities found in the midst of their situation, they revealed the need for empowerment to develop autonomy about their life contexts. The participation of women as protagonists of their lives, trained for daily life, was encouraged. In this moment of retrospective, the previously codified and decoded theme was returned to the Culture Circle for debate, seeking its reflection and discovery of the boundary situations, with the problematization for critical awareness:

I try to take care of my head, not thinking too much. Then I try to think of something else [...] you may experience depression, so I always try to keep busy with something [in the hospital]. Doing an activity, or talking to someone, a different subject ... in this matter, I try to focus more on my head not to stop, [...] so if you keep thinking, just focus on that [on stroke], you It ends up getting sick. So, I always think: wow, and if I get sick, who will take care of me? I thoughtso. (FC2)

To enrich the reflection on the highlighted themes, we discussed the importance of expressing the feelings of the participants in the Culture Circles. These feelings referred to oppression as women housewives, who themselves assumed responsibility for care and perceived barriers to care in the hospital setting. The family caregivers acknowledged that Stroke Unit's multidisciplinary team could act as support for clarifications related to stroke condition and necessary care, as well as provide social support and mediate family conflicts for the division of care.

The moment also provided a relaxed dialogue about the daily life stories of the participants of the Culture Circle. It made possible the strengthening of their experiences, as a space for relief from anguish and fraternization. The development of these Culture Circles allowed a new look at family issues, in which participants sought strategies to overcome existing barriers:

There was no one to stay in the morning with Mom. Then I spoke to my brother and the two sisters. They stayed one afternoon and another night. So, I needed one in the morning, and I'll be in the afternoon, I can't stay all day [...] I took action, I told my brothers to help each one a little. (FC6)

The fact that the participants were able to express their feelings about the difficulties as caregivers contributed to reflection and overcoming the limit situations, paving the way for empowerment. The family caregivers revealed that the meetings provided an open space for dialogue with the recognition of experiences, real needs and exchange of experiences that helped them to unveil the obstacles they experience, most of the time alone and without family support.
Although their realities were initially veiled, it was possible to visualize the action-reflection-action process at the end of the discussions. The participants began to look for strategies to cope with limit situations, strongly characterizing psychological empowerment as a process (developed in Paulo Freire's Research Itinerary) and a result (possibility of change).

Among the strategies found are the search for a support network that goes beyond family boundaries, empathy and solidarity with other participants, the possibility of occupying their routines with other issues that pertain to those related to the family member with stroke, the identification of the latent need to develop skills for care after discharge, the possibility of self-care in the midst of the scenario experienced and the possibility of adapting routines, taking action in situations that interfere with overload.

At the last meeting, the participants described what their participation experience was like. The closing took place in a relaxed manner, bringing the participants closer to the group, revealing their potentialities, limitations and strengths, favored by the research context and method adopted. The participants were more clear about their care for the person with stroke, visualizing the possibility of self-care, even in this challenging context, promoting the quality of life and the awakening of principles such as perseverance, positivity, collaboration, coresponsibility and solidarity.

\section{DISCUSSION}

In the hospital environment, the progressive demand for beds, the search for shorter periods of hospitalization and the predominance of actions focusing on the disease culminate in a barrier to establishing adequate conditions for the individual's full recovery and preparation for discharge. As a subsequent protagonist of care for the dependent person, the family faces a challenging situation, finding themselves "required" to seek tools that allow adequate care in the home environment, usually exercising informally and without remuneration ${ }^{(12)}$.

The definition of care is permeated by conflicting moments in the family environment. It should be noted that the responsibility usually rests with the person who has the most time available to be with the dependent. Research developed traces the profile of female caregivers, usually with kinship, such as daughter and wife. The average frequent age ranges from 45 to 60 years, predominantly married, unemployed or domestic, with low education and already residing with the person in need of care. In addition, care sometimes required the participation of friends. These data corroborate the findings of this study ${ }^{(8,12-14)}$.

A study conducted in Portugal evaluated the satisfaction of family caregivers regarding hospital discharge planning, finding unsatisfactory indicators. About $30 \%$ of participants said they had not received any preparation for dehospitalization. This demonstrates that the hospital health team should give greater importance to sharing information about care, so as to help caregivers develop empowerment, positively interfering in the quality of life of the dependent person and the caregiver ${ }^{(12)}$.

The discussions showed that empowerment is incipient in the daily lives of caregivers, as they expressed feelings of anguish 
and despair for care of people with stroke, especially after hospital discharge. Participants expressed little attention from the health team about their needs and individualities for care in dehospitalization. However, authors state that hospital staff can listen to them and assist them in identifying alternatives to new arrangements that need to be made in their routines, encouraging participation and understanding ${ }^{(11)}$. Empowerment can be developed in the hospital environment, seen as a process and result that seeks transformations by fostering action and reflection on the reality of life, as well as promoting critical unveiling, permeated by dialogue $\mathrm{e}^{(15-16)}$.

For this Health Promotion strategy, it is necessary to be aware of its importance in the stroke care network, considering their wishes and previous family routines. Disabilities cross many sectors and, in addition to the person affected, involves family caregivers and the Health Care Network, which must ensure care at all times ${ }^{(17)}$.

The caregiver plays a fundamental role in the quality of life of the stroke survivor, since in most cases there is a dependence on the daily performance of the affected person. However, in this scenario, there is a physical and emotional burden on the caregiver, which leads to the need to consider him as a person who also has care needs $s^{(8,17)}$. Some precursors of this burden were identified in this study.They were stress and individual limits of family caregivers for this function, fragility in the support and social network, including family conflicts that directly interfere with the division of this attribution, the initial shock with transformation of family life after illness, added to new routines and lack of information and skills for care.

Amid the prevalence of Non-Communicable Chronic Diseases, the role of the caregiver intensifies, related to the predominance of dependent and disabled people. This demand for informal caregivers has led to an increase in discussions that include them in this process, understanding these people as key links that work together between the health team and the stroke person himself ${ }^{(6)}$.

In the early stages of this process, it is common for family caregivers to feel pressured to fulfill all their responsibilities and other functions that they had previously performed. This situation becomes stressful and painful as it is necessary to plan the family routine after discharge without disregarding the importance of taking care of oneself $f^{(18)}$. The health team assumes an indispensable role in the safe transition to the home, understanding the aspirations and changes in family roles that lead to actions for the development of skills and competences that assist in the transformation of routine enabling Health Promotion and quality of life ${ }^{(19)}$.

The World Health Organization recognizes the role of caregivers in the Global Disability Action Plan 2014-2021, which focuses on caregivers as key players in supporting people living with disabilities. Thus, it establishes the need for adequate support so that these people can perform care properly. It also highlights several actions directed at the caregiver, such as training and support, investments in technologies that can help people with limitations and, consequently, reduce the time spent and the physical and mental burden of caregivers ${ }^{(14)}$.

There is great potential for health promotion for caregivers in the hospital context. The actions are continuous and should be initiated from the admission of the person with stroke to the permission and identification of tools available for support in care, aiming, above all, that the caregivers are autonomous for social reintegration after discharge. These people need information, health education, training, support and encouragement in the possible situations that care entail ${ }^{(6,20)}$.

The Ottawa Charter establishes the development of personal skills as one of the fundamental axes for the implementation of health promoting actions, achieving a better quality of life for people and communities, as well as including their involvement in this process ${ }^{(3)}$. In this scenario of care for people hospitalized with stroke, it is up to the multidisciplinary team to train family caregivers, including coping with the chronic condition ${ }^{(8)}$. However, the statements of this study did not identify these practices, which may explain the obstacle for participants to visualize their role after discharge and develop empowerment. Although some family report that they help in care, there was no relationship of these functions from an appropriate guidance by the multidisciplinary team, pointing to the question of the appropriate development of these skills.

The task of care also reflects on economic and financial issues, as the dependence of the person with stroke increases ${ }^{(21)}$. A study of 30 caregivers found that more than half (66.7\%) assumed increases in economic spending. Therefore, the team can identify and meet these demands, such as information on drug care, hygiene, mobilization, adjustments to the physical structure of the household, access to health services and necessary equipment and task management ${ }^{(12)}$.

The period after the acute phase of stroke has been shown as the most stressful moment for the informal caregiver, apprehension also observed in this study with the participants. There is an imperative that the first weeks after stroke can be characterized as the best time to put interventions into practice, targeting the hospitalized person and their caregiver. Thus, a safe transition to the home can be guaranteed, reducing both anxiety and enabling empowerment so that they can positively influence functional recovery ${ }^{(19,22)}$.

One study developed a care model for informal caregivers of people after stroke, in which nurses sought problem solving via telephone by providing information about chronic condition and support. The authors point out that the empowerment process enables caregivers to be able to identify their own problems and autonomy to solve them ${ }^{(22)}$.

This preparation for care can be developed and developed in the hospital environment, based on a good relationship between the multidisciplinary team, family caregiver and person with stroke $^{(16)}$. However, in the present research, these practices were not observed, which hindered the empowerment of participants in the initial meetings.

At the end of the discussions, some family caregivers visualized changes in their routines and delimited actions to be developed, aiming at facing a new scenario. This was characterized as psychological empowerment, as it involved individual changes and assisted participants in adapting their borderline situations. However, in order to achieve collective transformations, it is important to share these skills with other people and groups who experience the same difficulties ${ }^{(10)}$. In a study conducted with the 
elderly in groups organized by the Family Health Strategy team, it was found that these spaces are beneficial for participants, since they promote moments of socialization, entertainment, health education, bonding and support network ${ }^{(23)}$. Group activities represent a mobilizing tool for empowerment and autonomy and, when linked to theater activities, Culture Circles, community therapy, therapeutic listening workshops and social action projects can complement these resources.

\section{Study limitations}

It was noticed that the different levels of dependence of people with stroke showed different confrontations of family caregivers about care relationship, which may be a research limit. During the study, the researcher met the hospitalized people and was able to observe their neurological sequelae and disabilities. Thus, it was observed the association of increased care burden to those who had family members with greater physical disabilities. However, the level of overload and dependence were not quantified in this study.

In addition, there was a variation in the period of hospitalization, between 2 and 15 days, which may have reflected in superficial perceptions of coping care to family caregivers with shorter experience in the context of the Stroke Unit.

\section{Contributions to health and nursing}

In addition to curative actions, since hospital admission, professionals must meet the needs of family caregivers. These actions aim to increase the ability to face the challenges that occur in care for the dependent person, so that they can develop empowerment and autonomy in decision making, transforming their family, social and economic contexts.

Health professionals working in this scenario should recognize factors of care overload and list strategies that can positively interfere with these items, facilitating the family caregiver's routine and enabling their participation in the care process. It is also understood that involving the family caregiver in the preparation for discharge becomes a tool to reduce the risk of complications, readmission of the person with stroke and improve the quality of life of the caregiver. In addition to these aspects, the participation of family caregivers in care for people with stroke contributes to the multidisciplinary team as it brings together the various fields of knowledge, in a joint effort to effectively promote their quality of life.

At the end of the research, there was positive feedback from the participants regarding the meetings, as it was a moment directed to her, in which they could exchange their experiences and anxieties with care.

\section{FINAL CONSIDERATIONS}

The present study revealed that family caregivers rely on the work of the multidisciplinary team in the rehabilitation of stroke patients in the hospital environment, focusing on the disease. However, they have specific needs and anxieties in some skills inherent to the care process, more specifically in the distancing of empowerment to perform the function after discharge. The data bring the fragility of family support, as participants were unable to unveil the difficulties that will be encountered in changing daily routines.

The action-participant research method made it possible to grasp important information to answer the research objective. The dialogue and interaction developed between the researcher and the participants were fundamental to emerge the real needs. The application of Paulo Freire's Research Itinerary was challenging, as in the hospital context there are a number of pre-established routines.

Further studies that cover the family caregiver after dehospitalization are recommended. It is believed that they will be able to identify new demands and different challenges that may be addressed in the hospital context, especially considering that this person will have experienced the attribution of care for a long time.

Thus, it is relevant to debate the theme of empowerment, with a view to developing critical awareness of people in society. It is urgent to promote spaces of emancipation that seek cultural action for liberation, social transformation and the achievement of health equity.

\section{REFERENCES}

1. Bezerra IMP, Sorpreso ICE. Concepts and movements in health promotion to guide educational practices. J Hum Growth Dev [Internet]. 2016 [cited 2019 Jan 10];26(1):11-6. Available from: http://www.revistas.usp.br/jhgd/article/view/113709/112279

2. Heidemann ITSB, Cypriano CC, Gastaldo D, Jackson S, Rocha CB, Fagundes E. A comparative study of primary care health promotion practices in Florianópolis, Santa Catarina State, Brazil, and Toronto, Ontario, Canada. Cad Saúde Pública [Internet]. 2018 [cited 2018 Dec 18];34(4). Available from: http://www.scielo.br/pdf/csp/v34n4/1678-4464-csp-34-04-e00214516.pdf

3. World Health Organization. Ottawa Charter For Health Promotion. Ottawa: World Health Organization/Health and Welfare Canada/Canada Public Health Association; 1986.

4. Freire RMA, Landeiro MJL, Martins MMFPS, Martins T, Peres HHC. Taking a look to promoting health and complications' prevention: differences by context.Rev Latino-Am Enfermagem [Internet]. 2016 [cited 2018 Dec 15];24:1-9. Available from: http://www.scielo.br/pdf/rlae/v24/01041169-rlae-24-02749.pdf

5. World Health Organization. Standards for Health Promotion in Hospitals. [Internet]. 2004[cited 2019 Sep 6]. Available from: http://www. euro.who.int/_data/assets/pdf_file/0006/99762/e82490.pdf

6. Ramos EC, Castillo VAM. Prevalenciadel síndrome de sobrecarga y sintomatología ansiosa depresivaenel cuidador del adulto mayor. Psicología y Salud[Internet]. 2017 [cited 2019 Jan 14];27(1):53-9. Available from: http://revistas.uv.mx/index.php/psicysalud/article/view/2436/4287 
7. World Health Organization. World health statistics 2017: monitoring health for the SDGs, Sustainable Development Goals [Internet]. Geneva; 2017[cited 2019 Jan 14]. Available from: http://apps.who.int/iris/bitstream/handle/10665/255336/9789241565486-eng.pdf;jsessionid=DEE0 6CC1B44AB23401B445E149958172? sequence=1

8. Viegas LM, Fernandes AA, Veiga MAP. Nursing intervention for stress management in family caregivers of dependent older adults: a pilot study. Rev Baiana Enferm [Internet]. 2018 [cited 2019 Feb 17];32:1-12. Available from: https://portalseer.ufba.br/index.php/enfermagem/ article/download/25244/15967

9. $\quad$ Freire P. Pedagogia do Oprimido. 60ª ed. Rio de Janeiro: Paz e Terra; 2016.

10. Souza JM, Tholl AD, Córdova FP, Heidemann ITSB, Boehs AE, Nitschke RG. The practical applicability of empowerment in health promotion strategies. Ciênc Saúde Coletiva [Internet]. 2014 [cited 2018 Nov 01];19(7):2265-76. Available from: https://www.scielo.br/pdf/csc/ v19n7/1413-8123-csc-19-07-02265.pdf

11. Olivier CL, Phillips J, Roy DE. To be or not to be? A caregiver's question: the lived experience of a stroke family during the first 18 months poststroke. Scand J Caring Sci [Internet]. 2017 [cited 2018 Oct 25];32(1):270-9. Available from: https://onlinelibrary.wiley.com/doi/ full/10.1111/scs.12458

12. Pereira JFS, Petronilho FAS. Satisfaction of the family caregiver about the hospital discharge planning. RIE [Internet]. 2018 [cited 2019 Jan 16];22(2):42-55, 2018.Available from: http://repositorium.sdum.uminho.pt/bitstream/1822/53799/1/RIE_Satisfacao\%20do\%20FC\%20 sobre\%200\%20planeamento\%20da\%20alta\%20hospitalar_N\%C2\%BA22\%2c\%20Serie\%202\%20-\%20fev2018.pdf

13. Totsika V, Hastings RP, Vagenas D. Informal caregivers of people with an intellectual disability in England: health, quality of life and impact of caring. Health Soc Care Community [Internet]. 2017 [cited 2019 Feb 05];25(3):951-61. Available from: https://onlinelibrary.wiley.com/doi/ pdf/10.1111/hsc.12393

14. World Health Organization. WHO Global disability action plan 2014-2021. Better health for all people with disability [Internet]. Geneva, 2015 [cited 2018 Oct 06]. Available from: http://apps.who.int/iris/bitstream/handle/10665/199544/9789241509619_eng.pdf?sequence=1

15. Heidemann ITSB, Dalmolin IS, Rumor PCF, Cypriano CC, Costa MFBNA, Durand MK. Reflections on Paulo Freire's Research Itinerary: contributions to health. Texto Contexto Enferm [Internet]. 2017 [cited 2019 Jan 19];26 (4). Available from: http://www.scielo.br/pdf/tce/ v26n4/en_0104-0707-tce-26-04-e0680017.pdf

16. Wahlin I. Empowerment in critical care - a concept analysis. Scand J Caring Sci [Internet]. 2017 [cited 2019 Feb 20];31(1):164-74. Available from: https://onlinelibrary.wiley.com/doi/pdf/10.1111/scs.12331

17. Faleiros AH. Os desafios do cuidar: revisão bibliográfica, sobrecargas e satisfações do cuidador de idosos. Janus, Lorena [Internet]. 2015 [cited 2019 Jan 25];12(21):59-68. Available from: http://fatea.br/seer/index.php/janus/article/viewFile/1793/1324

18. Glauger JE. The longitudinal ramifications of stroke caregiving: a systematic review. Rehabil Psychol[Internet]. 2010 [cited 2018 Dec 02]; 55(2): 108-25. Available from: https://www.researchgate.net/ publication/44625046_The_Longitudinal_Ramifications_of_Stroke_Caregiving_A_Systematic_Review

19. Sit JWH, Chair SY, Choi KC, Chan CWH, Lee DTF, Chan AWK et al. Do empowered stroke patients perform better at self-management and functional recovery after a stroke? a randomized controlled trial. Clin Intervent Aging [Internet]. 2016 [cited 2018 Dec 08];11:1441-50. Available from: https://www.ncbi.nlm.nih.gov/pmc/articles/PMC5072569/

20. Pucciareli G,Vellone E, Savini A, Simeone S, Ausili D, Alvaro R et al. Roles of changing physical function and caregiver burden on quality of life in stroke. Stroke [Internet]. 2017 [cited 2019 Jan 15];48(3):733-39. Available from: https://www.ahajournals.org/doi/pdf/10.1161/strokea ha.116.014989?download=true\&

21. Longacre M, Valdmanis VG, Handorf EA, Fang CY. Work impact and emotional stress among informal caregivers for older adults. J Gerontol B Psychol Sci Soc Sci [Internet]. 2016 [cited 2018 Dec 01];72(3):522-31. Available from: https://academic.oup.com/psychsocgerontology/ article/72/3/522/2631929

22. Graf R. The stroke caregiving trajectory in relation to caregiver depressive symptoms, burden, and intervention outcomes. Top Stroke Rehabil [Internet]. 2017 [cited 2019 Feb 8];24(7):488-95. Available from: https://www.ncbi.nlm.nih.gov/pubmed/28618848

23. Lange C, Heidemann ITSB, Castro DSP, Pinto AH, Durand MK.Promoting the autonomy of rural older adults in active aging. Rev Bras Enferm [Internet]. 2018[cited 2019 Sep 9];71(5):2411-17. Available from: http://www.scielo.br/pdf/reben/v71n5/0034-7167-reben-71-05-2411.pdf 